\title{
Water availability effect on transpiration of the Norway spruce forest stand: a case study
}

\author{
Bužková, R. ${ }^{* 1,2)}$, Pokorný, R. ${ }^{1,3)}$ \\ ${ }^{1)}$ Department of Ecosystem Analysis, Global Change Research Centre Academy of Sciences of the \\ Czech Republic, Bèlidla 986/4a, CZ-60300 Brno, Email:buzkova.r@czechglobe.cz \\ ${ }^{2)}$ Department of Forest Ecology, Mendel University, Zemédẻlská 3, CZ-613 00 Brno, Czech Republic \\ ${ }^{3)}$ Department of Silviculture, Mendel University, Zemédèlská 3, CZ-613 00 Brno, Czech Republic
}

\begin{abstract}
Bužková, R., Pokorný, R. 2012: Water availability effect on transpiration of the Norway spruce forest stand: a case study. - Beskydy, 6 (1): 67-74

We have studied Norway spruce stand transpiration in socially differentitated forest in dense and sparse part. During dry conditions, codominant trees in forest sparse part transpired about $85 \%$ of total stand transpiration and in forest dense $92 \%$. Forests socially differentitated and less dense has a better biomass production potential with exception of extremely low soil water availability.
\end{abstract}

Keywords: sap flow, tree dominance classes, volumetric soil moisture content, specific sap flux

\section{Introduction}

When we want to evaluate water balance in any area, we are supposed to specify water input and output variables. Water inputs are horizontal and vertical precipitations. Water outputs are direct runoff, difference of the amount of water in a soil body, incerception and evapotranspiration (Allen et al. 1998). Evapotranspiration term consists of two separated processes: evaporation and transpiration. These processes occur simultaneously and it is not easy to distinguish between each other (Taiz, Zeiger 2002).

Evaporation represents a passive evaporation of water from the bare soil surface. Dense forest canopy layer might change amount of evaporated water into minimum values. Transpiration is an active evaporation of water from the opened stomata. Evaporation of water on the surface of the leaves has a significant coolling effect (Larcher 2003). Transpiration is one of the driving force of the movement of transpiration stream, when water and dissolved nutrients, sap, are transported from the root system into branches and leaves.

Amount of transpired water depends on species, soil moisture and micrometeorological parameters (Allen et al. 1998). Hight relative air humidity, e.g. low vapour pressure deficit, decreases cooling demands of the atmosphere. Soil moisture drives stomata closure. Hight air temperature and incident global radiation increases cooling demands. Wind blowing around leaves changes air humidity in the boundary layer of the leaf and contributes to the higher cooling demands (Larcher 2003). Norway spruce tree can release $40 \mathrm{~kg}$ (e.g. $4 \mathrm{~mm}$, stand density 1000 indiv. ha ${ }^{-1}$ ) of sap during good soil water availability conditions at the age of 30 years (Slipkova, Pokorny 2012).

Forest stand density and architecture determine water demand of the stand (Lundblad and Lindroth 2003). Tree dominance classes (TDC) separated according to the distribution of the DBH and social status has a different response of transpiration during moist and dry periods. Dominant trees are supposed to have the highest transpiration compared to the rest of TDC because of the need to cool assimilation aparatus more. Low amount of water in soil body results into shifted strategies of the TDC. Dominat trees need to spare water and actively close stomata. Codominant and subdominant trees has more available water and moreover they are shaded by dominant and codominant trees, respectively.

The aim of this study is to evaluate effect of stand density and soil moisture content on transpiration of the stand. 


\section{Material and Methods}

Measurements were carried out in the Norway spruce stand (Picea abies [L.] Karst.) located at the Experimental Ecological Study Site of Bily Kriz in the Moravian-Silesian Beskydy Mountains (908 a.s.l., $49^{\circ} 30^{\prime} \mathrm{N}, 18^{\circ} 32^{\prime} \mathrm{E}$ ) in the Czech Republic. Climate conditions can be characterized as cold (mean annual mean temperature of $5^{\circ} \mathrm{C}$ ) and humid (annual mean air humidity of $80 \%)$. The geological bedrock is formed by Mesozoic Godula sandstone (flysch type) and the soil type is haplic podzol (FAO classification). Growing season lasts 190 days on average over the last 10 years (Pokorný et al. 2008). Mean annual precipitation is of $1306 \mathrm{~mm}$ over period 1998-2011.

Norway spruce stand was artificially established by 4-year old seedlings in 1981. Since 1992, there are two research plots with area of 0.25 ha each with different stand density: forest sparse (FS) and forest dense (FD). At the end of each growing season, forest inventory measurement is performed. For our investigation, we have chosen a growing season in 2003 (see Tab. 1). Diameter at breast height (DBH) was measured by meter and tree height by Forestor Vertex (Haglöf SB, Sweden). DBH growth dynamic was measured by the dendrometric bands (DB 20, EMS Brno, Czech Republic) on 25 trees in each stand 13 times during the growing season.

In order to study potentially different response of the trees with different social status in the forest stands, tree dominance classes (TDC) were defined as i) subdominant (FS < 9.2. FD < 10.5), ii) co-dominant (FS $11.7 \pm 2.5$, FD $12.0 \pm 2.5$ ) and iii) dominant (FS $>14.2$, FD $>14.5$ ). Tresholds between TDC were defined after analysis of the DBH distribution in both forests with respect to the observation of $\mathrm{DBH}$ and social status of the trees in the field. Number of tree individuals of the each TDC was evaluated too.

Sapwood area (SA) evaluation of both stands was based on allometric relation $\mathrm{SA}=0.537 \mathrm{xDBH}^{2.0791}$ (Pokorný, Tomášková 2007). SA of every tree individual was calculated by this relationship. Total of each individual tree sapwood area was equal to sapwood area of both stands (see Tab. 1). SA of both stands was divided proportionaly to the number of tree individuals into SA of each TDC.

Measurement of sap flow was performed by HPV technique (Heat Pulse Velocity) using a sap flow-meter SF 300 (Greenspan Technology, Australia). Measured data were processed by SAPCAL software (Greenspan Technology, Australia). Calculation of the sap flow velocity was processed by method decribed in Smith, Allen (1996). Sampled tree individuals were selected according to TDC, when sap flow was measured on two trees per each TDC Number of sampled trees was two per each TDC in both forests. Sampled individuals were representative for the TDC according to the DBH and position status in the stand. Radial profile measurement of the sap flow was perfomed (unpublished data). According to this measurement, sap flow sensors were inserted into $20 \%$ and $60 \%$ of sapwood depth in order to measure mean sap flow. Tree individual specific sap flux (SSF, $1 \mathrm{~h}^{-1} \mathrm{~cm}^{2}$ ) was calculated as a sap flux velocity divided by the tree sapwood area. Mean night-time SSF of each day was subtracted from all day-time SSF due to necessary correction for night-time flow. Forest stand transpiration was calculated as a mean individual SSF multiplied by the total SA of the stand TDC of both stands. In order to estimate daily sum of transpiration of the average tree, we

Tab. 1: Forest inventory characteristics of forest sparse (FS) and forest dense (FD) stands in growing season 2003.

\begin{tabular}{lcc}
\hline \multicolumn{1}{c}{ Stand characteristic } & FS & FD \\
\hline Height $(\mathbf{m})$ & $9.6 \pm 1.5$ & $12.0 \pm 1.5$ \\
Mean DBH $(\mathbf{c m})^{\mathbf{x}}$ & $11.7 \pm 2.6$ & $12.0 \pm 3.0$ \\
Tree density $\left(\right.$ indiv. $\mathbf{h a}^{-1}$ ) & 1820 & 2440 \\
Total sapwood area $\left(\mathbf{S A}, \mathbf{~ m}^{\mathbf{2}} \mathbf{h a}^{-1}\right)$ & 17.16 & 25.08 \\
LAI PCA mid, seasonal. maximum & 10.45 & 12.34 \\
Total stem biomass $\left(\mathbf{t ~ h a}^{-1}\right)$ & 32.84 & 48.08 \\
Total leaf biomass $\left(\mathbf{t ~ h a}^{-1}\right)$ & 16.29 & 23.70 \\
Total branch biomass $\left(\mathbf{t ~ h a}^{-1}\right)$ & 14.85 & 21.60 \\
Canopy closure & 0.185 & 0.020 \\
\hline
\end{tabular}

note.: DBH diameter at breast height, LAI PCA mid Leaf Area Index 
have divided total sum of transpiration by the number of individuals of the forests.

Precipitation amount data (ENVITECH, EMS, Brno) were collected on an open area near the stands. Leaf area index and canopy closure were measured by the plant canopy analyzer LAI 2000 (LI-COR, Lincoln, NE, USA) seven times during growing season. Incident global radiation was continuously measured by the net radiometer (Kipp \& Zonen CM6B, Holland). Volumetric soil moisture content was measured by TRIME (TRIME-FM 2/3, Mesasystems Co., USA) in depth $17 \mathrm{~cm}$ in soil body once a day in five positions in each forest stand during growing season. Treshold of low soil moisture content (pernament whilting point) was set on $12 \%$ according to the previous measurements in soil body.

Statistical analyses were performed in STATISTICA 9.0 program. Transpiration on monthly scale was compared by independent two samples t-test. Level of the statistical significance was set on $\alpha=0.05$.

\section{Results}

Studied growing season can be characterized mainly by low amount of precipitation compared to previous years, when about $275 \mathrm{~mm}$ of water was missing in water budget of the forest. Volumetric soil moisture content did not reach treshold of pernament whilting point (under $12 \%$ ) in FS forest. However, low soil moisture was exceeded at the end of August and September in FD forest. (Fig. 1).

Due to the cultivation history, different stand architecture was observed. Despite almost the same mean DBH of both stands, trees in FS were lower for about $1.2 \mathrm{~m}$ compared to FD stand (Tab. 1).

Mean DBH increment was $1.2 \mathrm{~mm}$ in FD and $0.7 \mathrm{~mm}$ in FS, respectively. After 211 DOY $\left(30^{\text {th }}\right.$ July), DBH changes were almost constant until 230 ( $18^{\text {th }}$ August) for both forests stands, but in a different level of relative increment of DBH (Fig. 2).

Number of tree individuals in the FS and FD was 456 and 619. Tree dominance classes were represented by the subdominant (18\%), codominant $(65 \%)$ and dominant (17\%) trees in FS and by the subdominant (10\%), co-dominant $(69 \%)$ and dominant $(21 \%)$ in FD. Sapwood area of the stands was divided according to the percentage of TDC.

Forest stands has transpired $359.41 \mathrm{~mm}^{\text {day }}{ }^{-1}$ in FS and $475.41 \mathrm{~mm}^{\text {day }}{ }^{-1}$ in FD, respectively. Daily total of transpiration of the mean tree was $0.788 \mathrm{~mm}$ in FS and $0.768 \mathrm{~mm}$ in FD. Maximum transpiration values occured during May and June in FS (80 $\mathrm{mm} \mathrm{month}^{-1}$ ) and in August and September in FD in co-dominant trees $(145 \mathrm{~mm}$ month $^{-1}$ ). After comparison within stands, dominant trees transpired insignificantly more sap (8.99 $\mathrm{mm} \mathrm{month}^{-1}$ ) than subdominant trees (5.06 mm month ${ }^{-1}$ ) in FS. This difference was observed in FD too, when dominant trees transpired $6.40 \mathrm{~mm}^{\text {month }}{ }^{-1}$ and codominant trees $10.00 \mathrm{~mm}$ month $^{-1}$. Rain period during July showed much lower transpiration of codominant trees compared to the other TDC in both stands. Codominant TDC transpired maximally $92 \%$ of the total stand transpiration in both stands. During low volumetric soil moisture content, proportion of transpiration of codominant TDC were higher compared to the other periods.

On daily scale, SSF of codominant and subdominant trees was higher than SSF of dominant TDC in FS and FD during whole growing season. This pattern is represented by the selected day, 11.9. (Fig. 4). Volumetric soil moisture content was $17.5 \%$ in FS and $12.44 \%$ in FD, respectively. Total SSF was $0.3551 \mathrm{~h} \mathrm{~h}^{-1} \mathrm{~cm}^{-2}$ in FS and $0.199 \mathrm{l} \mathrm{h}^{-1} \mathrm{~cm}^{-2}$. Transpiration of the whole forests was $3.197 \mathrm{~mm}$ in FS and $1.119 \mathrm{~mm}$ in FD during this day. SSF of the dominant TDC was suppressed in FS as well as in FD.

\section{Discussion}

Amount of water available for the forest stands was a key factor for the transpiration and biomass growth pattern observed in growing season 2003. Transpiration of the co-dominant trees was prevailing in both density variants of the forest, because of the dominant trees are more exposed to the incident global radiation. Fluctuations of the transpiration during growing season were caused by the volumetric soil water content. In FD forest, more precipitation were needed to the significant change of ratio between TDC as observed in FS. Mean individual tree transpiration was similar for both forests, about $0.77 \mathrm{~mm}$, which is quite low amount of sap compared to the usual values (Slipková, Pokorný 2012). During presented day, low water availability closed to the pernament whilting point caused suppression of transpiration of all TDC in FD. Despite of the sampled tree number, an insight into the water demands of the forest can be provided. During dry periods, more dense forests suppress carbon assimilation process and transpiration decreases. Afterwards, biomass increment can be supressed or temporarily stopped. 


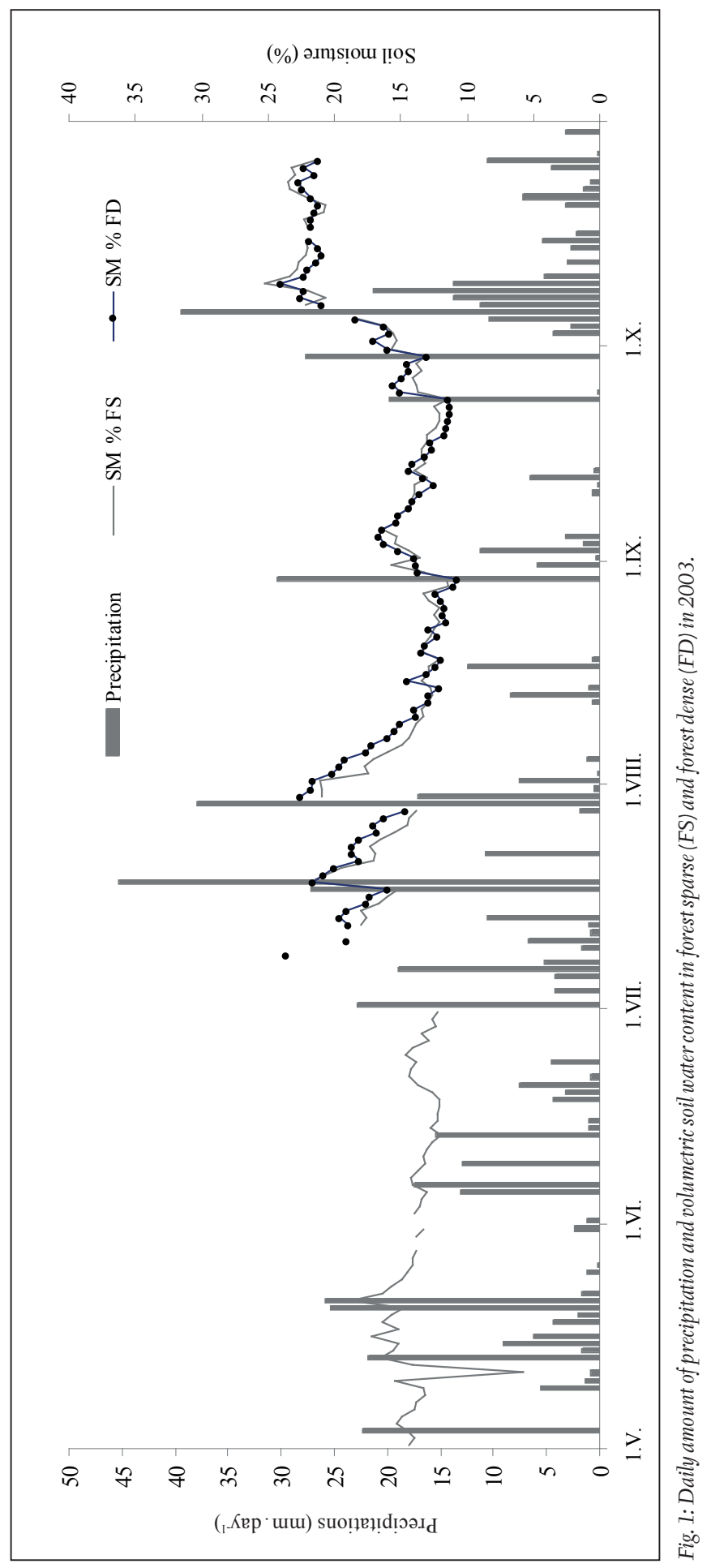




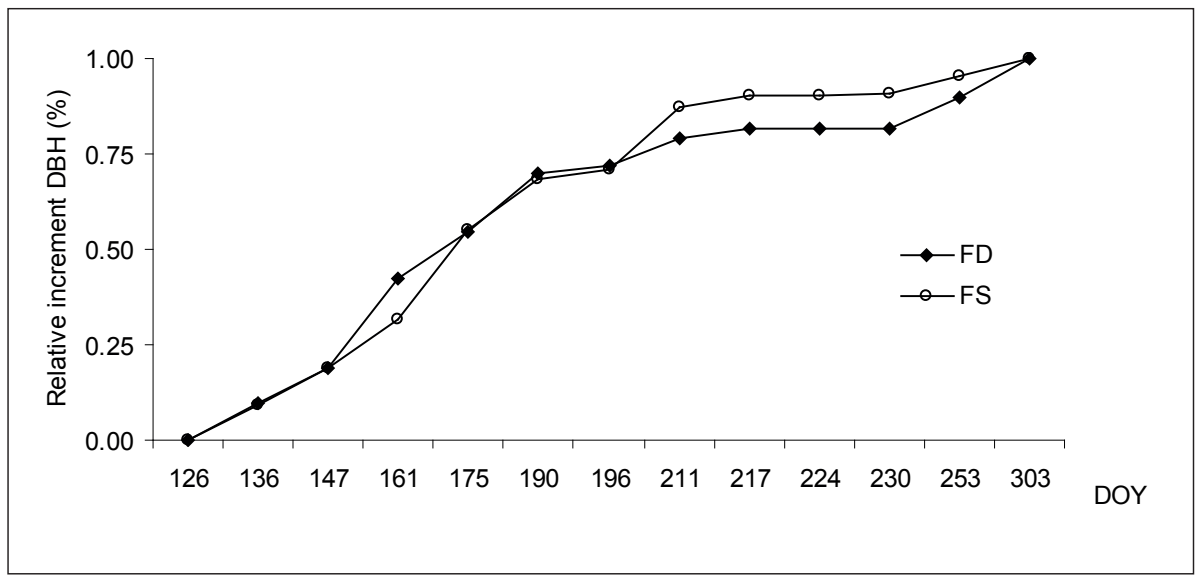

Fig. 2: Relative increment of DBH (\%) in forest dense (FD) and forest sparse (FS) during growing season 2003. DOY means day of the year.
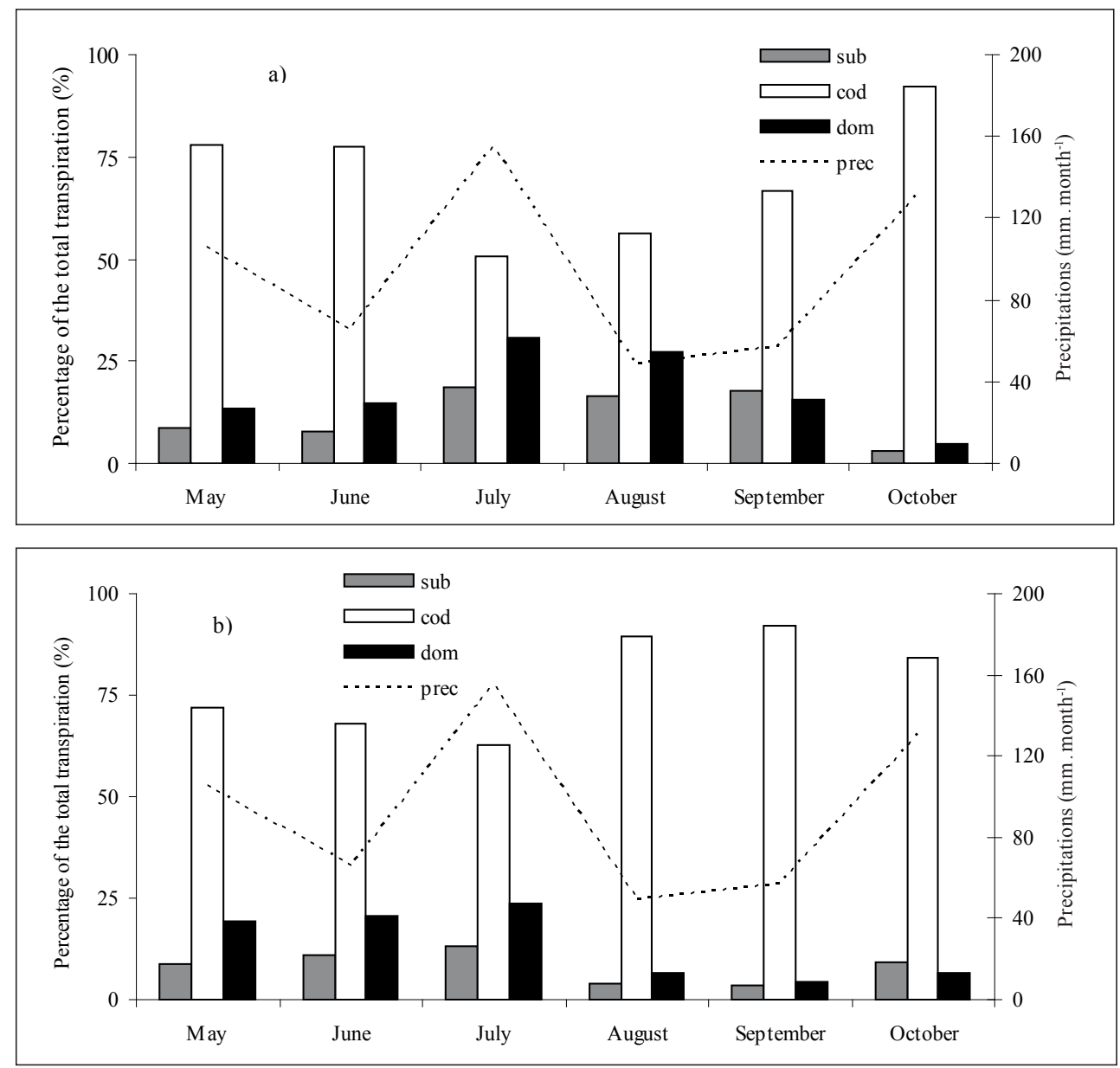

Fig. 3a, b: Monthly percentage of total stand transpiration of the forest sparse (FS) (a) and forest dense (FD) (b). Trees were divided into three tree dominance classes as subdominant (sub), codominant (cod) and dominant (dom). Amount of precipitation was included (prec). 


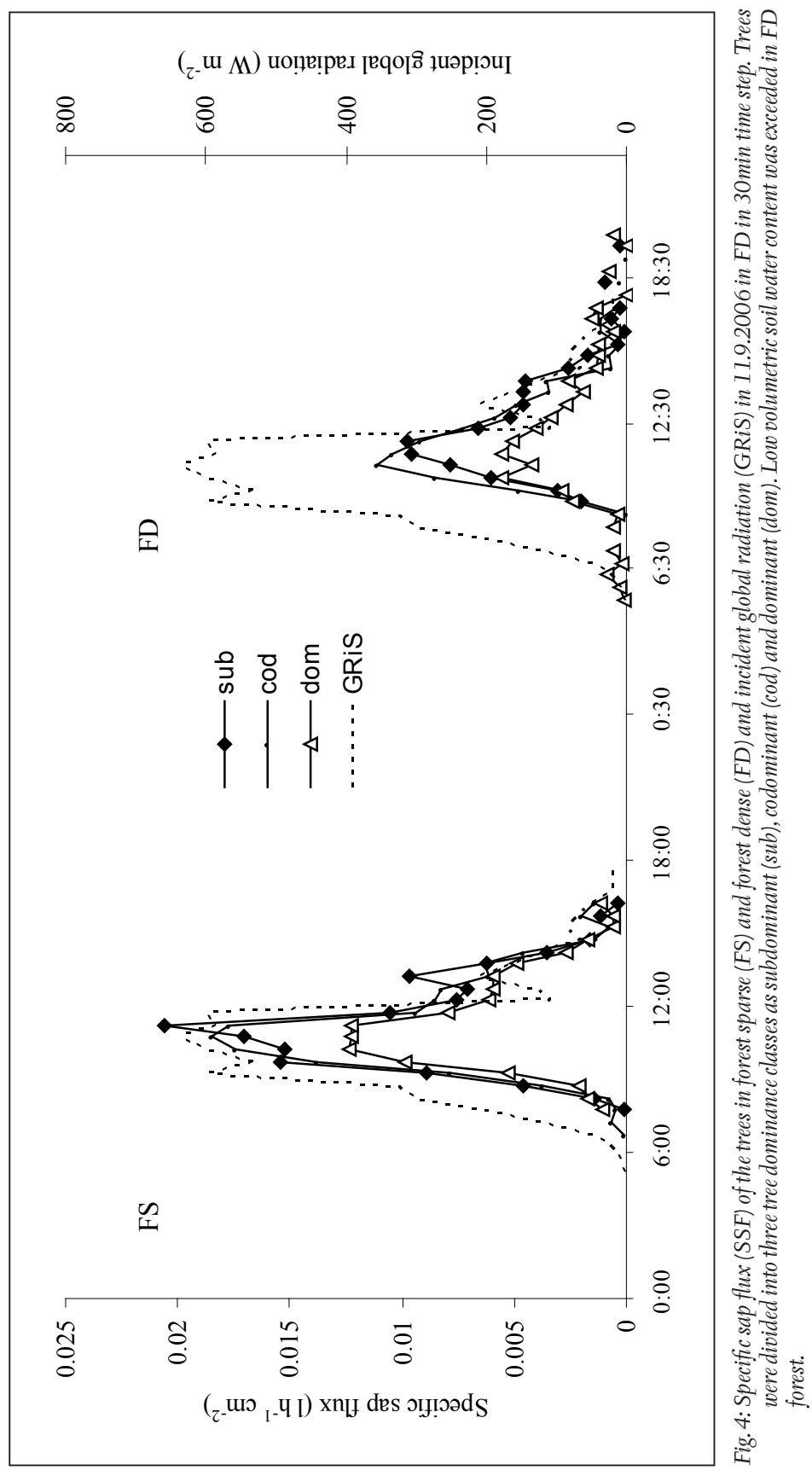




\section{Acknowledgements}

The authors are grateful for the financial support by grants no. SP/2dl/70/08 and SP/2dl/93/07 of the Ministry of Environment of the Czech Republic and CzechGlobe CZ.1.05/1.1.00/02.0073. We also thanks to the project OPVK Partnership Climate no. CZ.1.07/2.4.00/31.0056 and project GA (4.j.221/2010-49l/IGA).

\section{References}

Allen, R. G., Pereira, L. S., Raes, D., Smith, M. 1998: Crop Evapotranspiration (guidelines for computing crop water requirements). FAO Irrigation and Drainage Paper, No. 56.

LARChER, W. 2003: Physiological plant ecology. $4^{\text {th }}$ edn. Next Section. Physiological Plant Ecology. Berlin, Springer.

LundBLAd, M., LindRoth, A. 2002: Stand transpiration and sapflow density in relation to weather, soil moisture and stand characteristics. Basic and Applied Ecology, 243: 229-243.

PoKorný, R., ToMÁšKovÁ, I. 2007: Allometric relationships for surface area and dry mass of young Norway spruce aboveground organs. Journal of Forest Science, 53 (12): 548-554.

Smith, D.M., Allen, S.J. 2006: Measurement of sap flow in plant stems. Journal of Experimental Botany, 47 (305): 1833-1844.

SLIPKOVA, R., PoKorny, R. 2012: Long-term water use efficiency of young spruce forest. Acta Horticulturae (ISHS), 951: 293-299.

Tainz, L., Zeiger, E. 2002: Plant physiology, $3^{\text {rd }}$ edition. Sunderland, Mass: Sinauer Associates, Inc., 690 pp. 
